\title{
Union after multiple anterior cervical fusion 21 cases followed for 1-6 years
}

\author{
Carlos Villas ${ }^{1}$, Rodrigo Martínez-Peric ${ }^{1}$, Ricardo Preite ${ }^{2}$ and Raul H Barrios ${ }^{1}$ \\ Departments of Orthopedics and Traumatology, ${ }^{1}$ Navarra University Hospital, \\ Pamplona, Spain, and ${ }^{2}$ Rome University Clinic La Sapienza, Rome, Italy.
}

Correspondence: Dr. C. Villas, Departamento de Cirugía Ortopédica y Traumatología, Clínica Universitaria de Navarra, Av. Pío XII s/n 31008, Pamplona, Spain. Tel +34 48-255400. Fax -172294

\begin{abstract}
With a mean follow-up of 3 (1-6) years, we report on 21 patients who underwent multiple level cervical fusion, using autologous iliac crest grafts. Discectomies were performed in 14 patients and corpectomies in another 7. Instrumentation was used in all patients with corpectomies and in 2 patients who underwent 2-level and 3-level discectomies. Non-union occurred in 1 patient at 1 level. Graft displacement requiring reoperation was observed in 2 patients with massive corpectomies, in 1 of them as a consequence of trauma. In both patients complete bony fusion was obtained after reoperation and no other complications were observed. We conclude that the success rate with multiple-level fusion is comparable to that of single-level fusion when adequate fixation is achieved.
\end{abstract}

\section{INTRODUCTION}

It has been reported that the rate of non-union increases when fusion is attempted at multiple levels of the cervical spine; the reported rate is quite variable, ranging from none (Simmons and Bhalla 1969, Whitecloud and La Rocca 1976, Boni and Denaro 1982) to almost half of the cases (Connolly et al. 1965, Zdeblik and Bohlman 1989, Zdeblik and Ducker 1991). We report 21 cases of anterior decompression and fusion of multiple levels.

\section{PATIENTS AND METHODS}

Between 1986 and 1991, 21 consecutive patients underwent anterior cervical decompression and fusion of 2 or more levels at the University Clinic of Navarra (Table 1). 13 patients were men and 8 were women. The average age was 54 (37-72) years. Tumor cases were excluded from the study. The diagnoses were: spondylosis only in 8 , spondylosis and hemiated disc in 9, post-traumatic instability in 3, and cervical instability after laminectomy in 1 patient. The average follow-up was 3 (1-6) years. 
All patients had chronic cervical pain, 12 patients with radiculopathy and 6 patients with myelopathy. 13 patients underwent a 2-level discectomy and fusion with autogenous bone graft from iliac crest using the Smith-Robinson technique. In 1 of them who had post-traumatic instability, a Senegas plate was used (Figure). The level C5-7 was the most commonly involved, having been fused in 10 cases. A 3-level discectomy and fusion was performed in 1 patient using a Senegas plate. Corpectomies (partial vertebral body resection) were performed in 7 patients. In this group, 2 patients had 1 corpectomy, 2 patients had 2, 2 patients had 3 and 1 patient had 4 corpectomies. In order to achieve stability, plate fixation was used in all of them, a Senegas plate in 4 patients and $2 \mathrm{AO}$ T-plates in the other 3 . Tricortical iliac crest grafts were used in all patients. In total, 5 levels were fused in 1 patient, 4 in 2, 3 in 3 and 2 in 15 patients. The total number of levels fused was 52 in the 21 patients.

A right-sided anterior approach was used in all patients. The skin incision was done transversally or vertically. A needle was inserted into the disc, and radiographic proof of the exact level was obtained. Once the appropriate level was confirmed, cervical disc excision or corpectomy were performed, leaving the adjacent end-plates free of cartilage. The posterior longitudinal ligament was preserved to maintain stability. A tricortical iliac crest graft fashioned into a horseshoe shape was placed in the defect created, providing some degree of distraction. When corpectomies were performed, a correctlysized tricortical graft spanning the extreme vertebrae was used. When posterior stability was compromised or extensive corpectomy was done, additional fixation was required. In these cases the plate was secured to the intact vertebral bodies with bicortical screws parallel to both end-plates. Anteroposterior and lateral radiographs were obtained intraoperatively to confirm vertebral alignment. An international occiputmentonian support brace was used during 6 weeks by all patients, followed by the use of Philadelphia collar until radiographic fusion was observed.

Radiographic controls were done 6 weeks, 12 weeks, 3 months and 6 months after surgery. All radiographs were reviewed with particular attention to fusion, graft collapse and displacement. A fusion was considered solid when bony trabeculae bridged the entire length of the fusion and when there was no movement between the fused segments on radiographs in extension compared to flexion. A persistent lucent line after 1 year was considered a non-union. A graft was considered to have collapsed when a loss of height greater than $2 \mathrm{~mm}$ was noted between the intraoperative and postoperative films. A graft was considered to be displaced when more than $2 \mathrm{~mm}$ of displacement occurred between the intraoperative and postoperative films.

\section{RESULTS}

There were no major complications. No patient had wound infections or other complications at the bone graft donor site.

Fusion was obtained in all patients but 1 , at 1 level. The average fusion time after discectomy was 3 (2-5) months and after corpectomy 4 (3-6) months. We observed a positive correlation between the number of fused segments and the time for fusion. No graft collapse was observed in this series, except in the case with non-union. 
Displacement of the graft with kyphotic deformity requiring reoperation occurred in 2 patients. The first one, with spondylosis, underwent C3-7 arthrodesis with 2 AO Tplates without graft screw fixation. 2 weeks after surgery the patient devloped delirium tremens. The graft was displaced posteriorly in consequence of a fall. An open reduction and screw fixation of the graft was performed. Complete bony fusion was observed after 6 months. The second patient, who had postlaminectomy instability and an osteophytosis myelopathy, underwent C6 and C7 corpectomies without internal fixation. The graft was displaced anteriorly 10 days after surgery. After reduction and fixation with a Senegas plate, consolidation was observed in 4 months.

Non-union was observed at 1 level in 1 patient who underwent 2-level discectomy without internal fixation. The graft was partially resorbed. The patient was asymptomatic. No posterior surgery was performed.

\section{DISCUSSION}

The most relevant question is whether the non-union rate increases when anterior cervical fusion is attempted at more than 1 level. This may be due to increased graft mobility which can be solved in some cases by adding an anterior plate (Senegas and Gauzere 1976, Morscher et al. 1986) or by performing a posterior cervical fusion (Farey et al. 1990). Our study indicates that the Senegas and AO plates provide satisfactory fixation.

As we have found in our series, particularly in cases with multiple corpectomies, there is a high risk of graft displacement when stability is not obtained. Stable internal fixation prevents graft dislocation and non-union in patients operated on with multilevel anterior vertebral interbody fusion.

\section{REFERENCES}

1. Boni M, Denaro V. Traitement chirurgical des cervicarthroses. Revision à distance (2-13 ans) des 100 premiers cas opérés par voie anterieure. Rev Chir Orthop Reparatrice Appar Mot 1982; 68 (4): 269-80.

2. Connolly E S, Seymour R J, Adams J E. Clinical evaluation of anterior cervical fusion for degenerative cervical dise disease. J Neurosurg 1965; 23 (4): 431-7.

3. Farey I D, McAfee P C, Davis R F, Long D M. Pseudarthrosis of the cervical spine after anterior arthrodesis. Treatment by posterior nerve-root decompression, stabilization, and arthrodesis. J Bone Joint Surg (Am) 1990; 72 (8): 1171-7.

4. Morscher E, Sutter F, Jenny H, Olerud S. Die vordere Verplattung der Halswirbelsäule mit dem Hohlschrauben-Plattensystem aus Titanium. Chirurg 1986; 57 (11): 702-7.

5. Senegas J, Gauzere J M. Plaidoyer pour la chirurgie anterieure dans le traitement des traumatismes graves des cinq dernières vertebres cervicales. Rev Chir Orthop Reparatrice Appar Mot (2 suppl) 1976; 62: 123-8.

6. Simmons E H, Bhalla S K. Anterior cervical discectomy and fusion. A clinical and biomechanical study with eight-year follow-up. With a note on discography: 
technique and interpretation of results, by Butt W P. Bone Joint Surg (Br) 1969; 51 (2): 225-37.

7. Whitecloud T S, La Rocca H. Fibular strut graft in reconstructive surgery of the spine. Spine 1976; 1 ( I ): 33-43.

8. Zdeblick T A, Bohlman H H. Cervical kyphosis and myelopathy. Treatment by anterior corpectomy and strutgrafting. J Bone Joint Surg (Am) 1989; 71 (2): 170-82.

9. Zdeblick T A, Ducker T B. The use of freeze-dried allograft bone for anterior cervical fusions. Spine 1991; 16 (7): 726-9. 


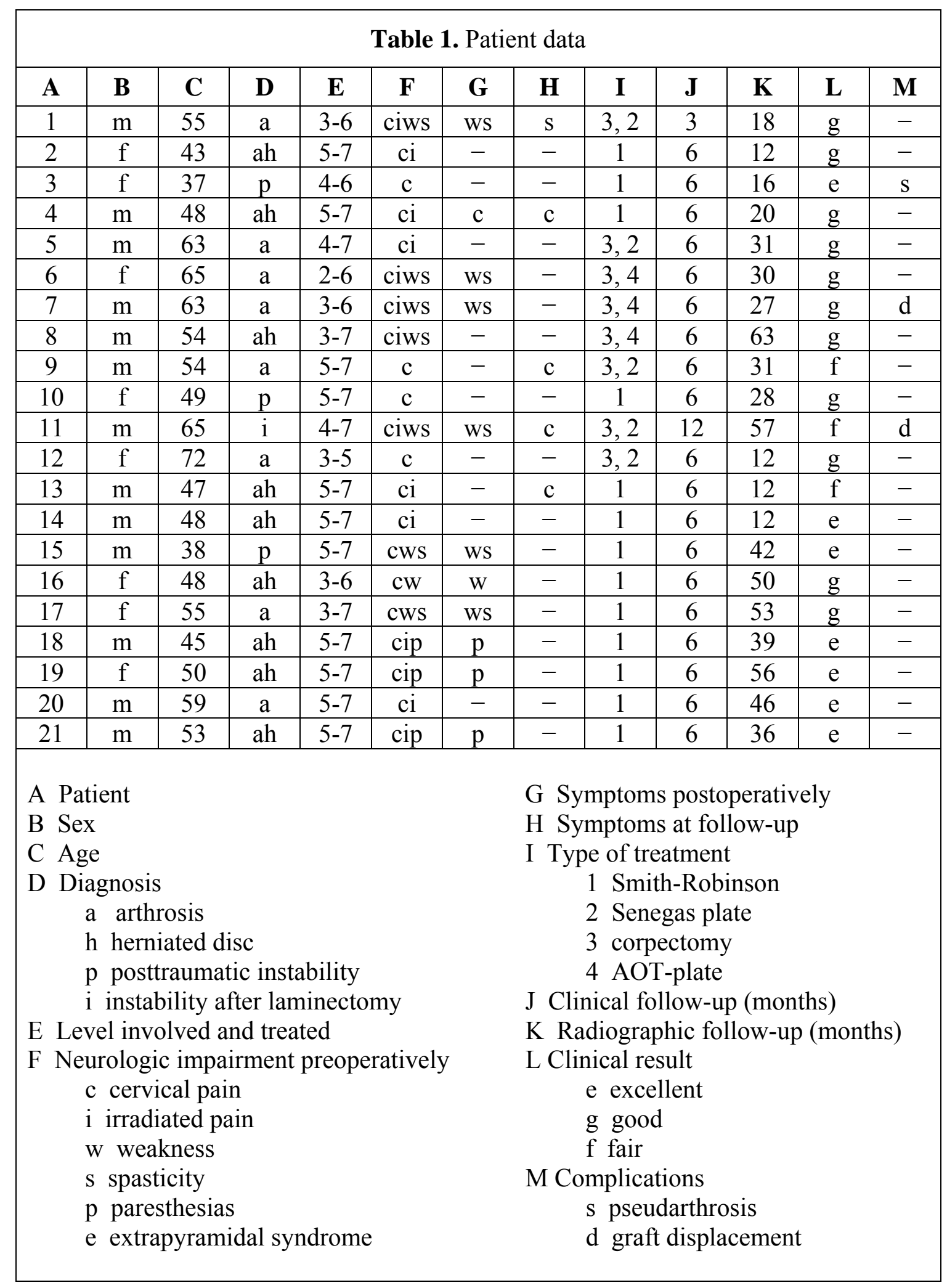




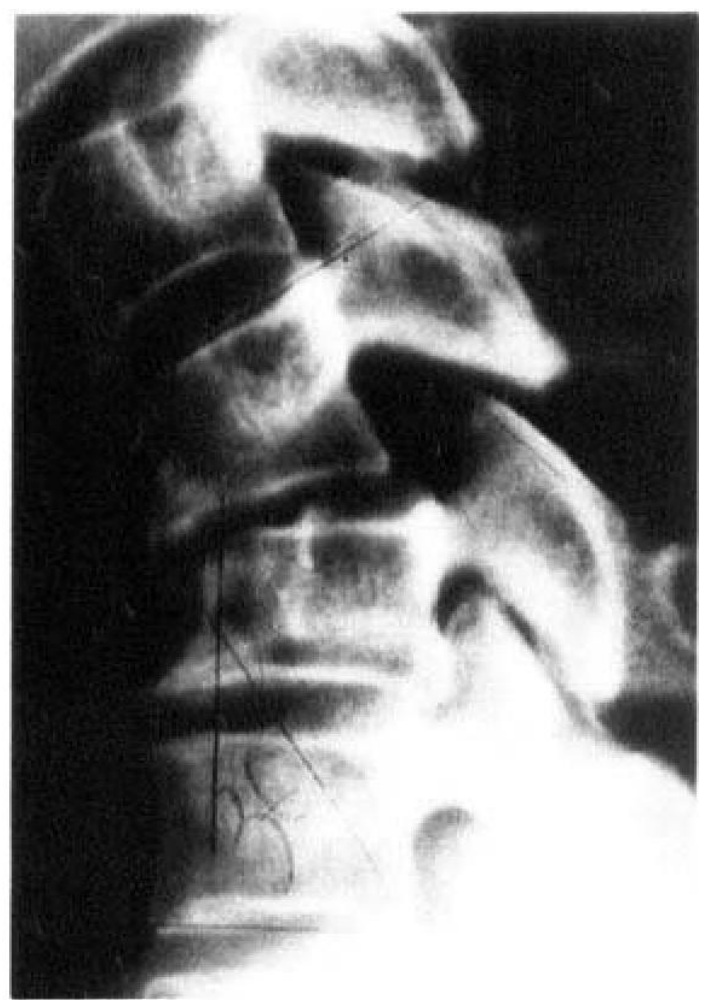

A 49-year-old woman with C5-C6 post-traumatic instability and C6-C7 spondylosis, without neurologic damage.

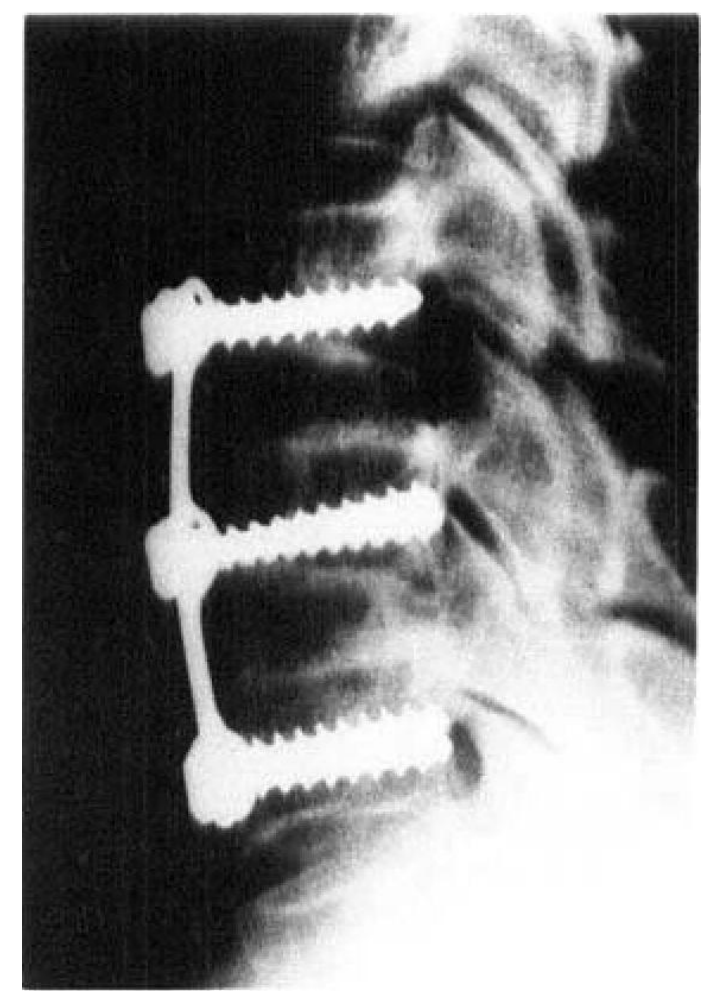

C5-C7 anterior fusion with a Senegas plate. 